\title{
Improving Fault Ride Through Capability of DFIG during RSC Flashover Fault
}

\author{
A. F. Abdou, Student Member IEEE, A. Abu-Siada, Senior Member IEEE and \\ H. R. Pota, Member IEEE, , N. K. Roy, Student Member
}

\begin{abstract}
Wind power generation is growing rapidly. However, maintaining the wind turbine connection to grid is a real challenge. Recent grid codes require wind turbines to maintain connected to the grid even during fault conditions which increases concerns about its sensitivity to external faults. So, researchers have given attention to investigating the impact of various external faults, and grid disturbances such as voltage sag and short circuit faults, on the fault ride through (FRT) capability of the doubly fed induction generator (DFIG). However, no attention has been given to the impact of internal faults on the dynamic performance of the machine when the fault occurs within the voltage source converters (VSCs) that interface the DFIG with the grid. This paper investigates the impact of the rotor side converter (RSC) IGBT flashover fault on the common coupling (PCC) reactive power and the FRT capability of the DFIG. A proper STATCOM controller to mitigate the effects of the flashover fault on the FRT is proposed. The DFIG compliance with numerous and recently released FRT grid codes under the studied fault, with and without the STATCOM are examined and compared. Furthermore, the capability of a proposed controller to bring the voltage profile at the point of PCC to the nominal steady-state level; maintain the unity power factor operation; and, maintain the connection of the wind turbine to the grid are examined.
\end{abstract}

Index Terms-DFIG, Flashover, STATCOM, FRT, VSC, RSC, GSC, Grid codes.

\section{INTRODUCTION}

T $\mathrm{N}$ recent years, wind energy has become one of the most 1 popular green renewable energy resources around the world, popular for its potential to offer clean, abundant electricity. The implementation of the carbon tax in some countries is considered as a trigger to accelerate the utilization of renewable energy sources. As a result, the use of wind energy is growing rapidly. In 2011 the wind energy production market grew 6\% as compared to 2010, and a 40.5 GW brought on line last year represents investments of more than $\$ 68$ billion [1]. The use of wind energy is still growing rapidly and it is expected to provide ten percent of the global electricity generation by the year 2020 [2]. Wind turbines can operate either with a fixed speed or a variable speed. In the case of fixed speed, the speed of the generator is fixed and determined by the grid frequency, gear ratio and the generator design. The fixed-speed wind turbine has the advantage of the low cost of

A. F. Abdou and H. R. Pota, and N. K. Roy are with the School of EIT, UNSW@ADFA, Canberra, Australia (e-mail: a.abdou@adfa.edu.au ) and (email: h.pota@adfa.edu.au ), and (e-mail: n.roy@adfa.edu.au).

A. Abu-Siada is with the Department of Electrical and Computer Engineering, Curtin University, Perth, WA 6845 Australia (e-mail: a.abusiada@curtin.edu.au). its electrical parts and of being simple, reliable, robust and well-proven. Its disadvantages are an uncontrollable reactive power consumption, limited power quality control and mechanical stress. Furthermore, all fluctuations in the wind speed are transmitted as fluctuations in the mechanical torque and then as fluctuations in the electrical power on the grid. The variable-speed turbine operation offers several major advantages over the fixed-speed operation, such as maximum power capture, less mechanical stresses, and less acoustical [3]. Among variable speed constant-frequency wind turbines, the doubly fed induction generator (DFIG) has been popular in the wind energy conversion systems (WECS) because it is a preferable choice in terms of size, cost, reduced losses and weight associated with the small converter [4]. The voltage source converters (VSCs) that interface with the DFIG and the ac grid are rated at $30 \%$ of the generator power capacity for a rotor speed range of $\pm 30 \%$ [5]. This makes the DFIG-based wind energy conversion system very sensitive to grid disturbances which may lead to catastrophic failure of the wind turbine and the converter switches if an adequate protection scheme is not installed $[6,7]$.

Wind turbine breakdown is attributable to defective / loose components or to malfunction in the turbine control systems. Statistical surveys indicate that about $38 \%$ of power converters failures are due to converter switches while 53\% of their failures are attributed to faults within converters control circuits [8]. Furthermore, a recent industry-based survey indicates that converter switches, and gate control circuits, are the most susceptible components in VSC faults [9]. Voltage source converters are subject to some common faults such as flashover [10-14]. Researchers have given attention to the dynamic performance of DFIG-based WECS during various grid disturbances such as load fluctuation, voltage sag and swell and short circuit faults on the grid side [15-20]. There are some studies about the effects of internal VSC faults on the performance of HVDC systems [21-23], but attention has not been given to investigate the impact of such faults on the PCC reactive power of the DFIG-based WECS and its compliance to recently developed grid codes [24, 25]. This paper investigates the impact of the RSC IGBT flashover fault on the fault ride through (FRT) capability of DFIGs. The compliance of the DFIG performance with numerous FRT grid codes is also investigated.

Flexible AC transmission systems (FACTS) based power electronic converters such as static synchronous compensator (STATCOM) is being used extensively in power system applications because of its ability to provide flexible reactive power flow control [26, 27]. STATCOM provides better reactive power support at low AC voltages compared with the 
static VAR compensator SVC as the reactive power from a STATCOM decreases linearly with the AC voltage. STATCOM has the ability to provide reactive power during voltage collapse with rapid response as it has no delay associated with the thyristor firing [28, 29]. A second aim of this paper is to use the STATCOM with a proper controller to mitigate the effect of this fault on the PCC reactive power of the DFIG-based WECS. Furthermore, improve the DFIG FRT capability to recently developed grid codes.

\section{SySTEM UnDER STUDY}

The system shown in Fig.1 is simulated to perform the investigation proposed in this paper. Fig.1 shows the stator of DFIG is connected to the grid through a short transmission line and a coupling transformer, while the rotor windings are fed through back-to-back IGBT-based voltage source converters with a common DC-link capacitor and chopper to limit the over-voltage of the capacitor. The grid side converter (GSC) and the RSC of the DFIG are controlled by a vector control as detailed in [30,31] and briefly elaborated below.

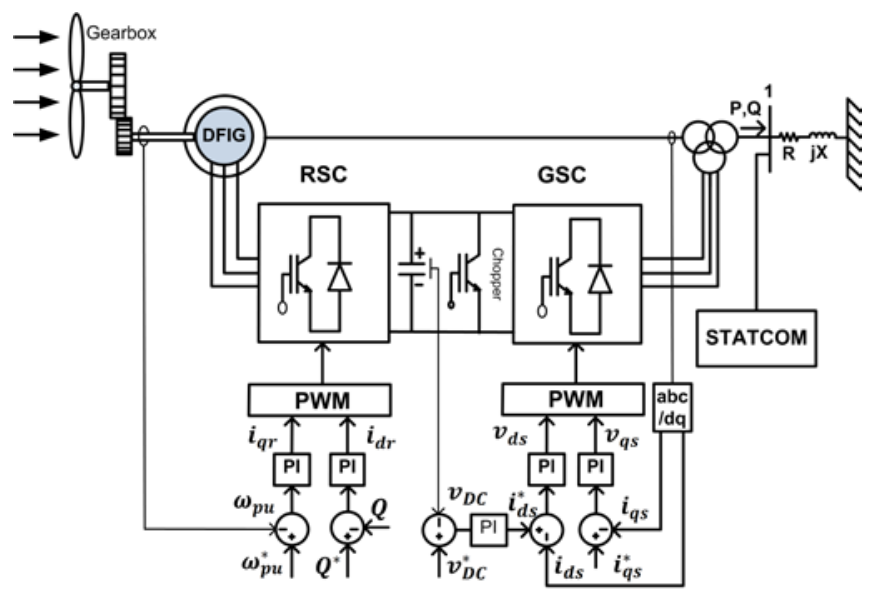

Fig. 1 System under study

The main task for GSC is to control the power exchange between the AC grid and the DC-link to maintain the DC voltage across the capacitor within permissible levels. In this context, a proper reference level for the d-axis stator current $i_{\mathrm{ds}}^{*}$ is created using the voltage error signal across the DC-link capacitor. $i_{\mathrm{ds}}^{*}$ is compared with $i_{\mathrm{ds}}$ to create an error signal that is used as an input to a proportional-integral (PI) controller. The level of q-axis reference current $i_{\mathrm{qs}}^{*}$ is selected to control the reactive power transfer between the GSC and the grid. The grid side controller output is used as an input to the pulse width modulation (PWM) circuit to create appropriate firing pulses for the GSC switches.

The RSC controls the generated active power according to the wind speed and the wind turbine characteristics, while the reactive power command is set according to the utility requirements. A reference speed $\omega_{p u}^{*}$ is selected based on the wind turbine characteristics to track the maximum power, and it is compared with the measured rotor speed to create an error signal that is fed to a PI controller to generate the q-axis rotor current $i_{q r}$. To achieve unity power factor operation, the reactive power reference $Q^{*}$ is set to zero and is compared with the measured value to create an error signal that is fed to another PI controller to generate the rotor d-axis current $i_{d r}$. The controller output currents are used as input to the RSC PWM circuit to create appropriate firing pulses for the RSC switches.

\section{STATCOM MODELING}

The STATCOM is working mainly as a regulating device, and it becomes an alternative option to a fixed reactive source. It provides the desired reactive-power generation or absorption. The STATCOM has a voltage source converter (VSC) with a capacitor on the dc side. The VSC is modeled as a six-pulse PWM GTO converter with a DC-link capacitor. The interaction between the AC system voltage and the voltage at the STATCOM AC terminals controls the reactive power flow. The STATCOM behaves as an inductor, if the system voltage is higher than the voltage at the STATCOM terminal. On the other hand, it will behave as a capacitor if the system voltage is less than the voltage at the STATCOM terminals. Under normal operating conditions, both voltages will be equal and there will be no power exchange between the STATCOM and the AC system.

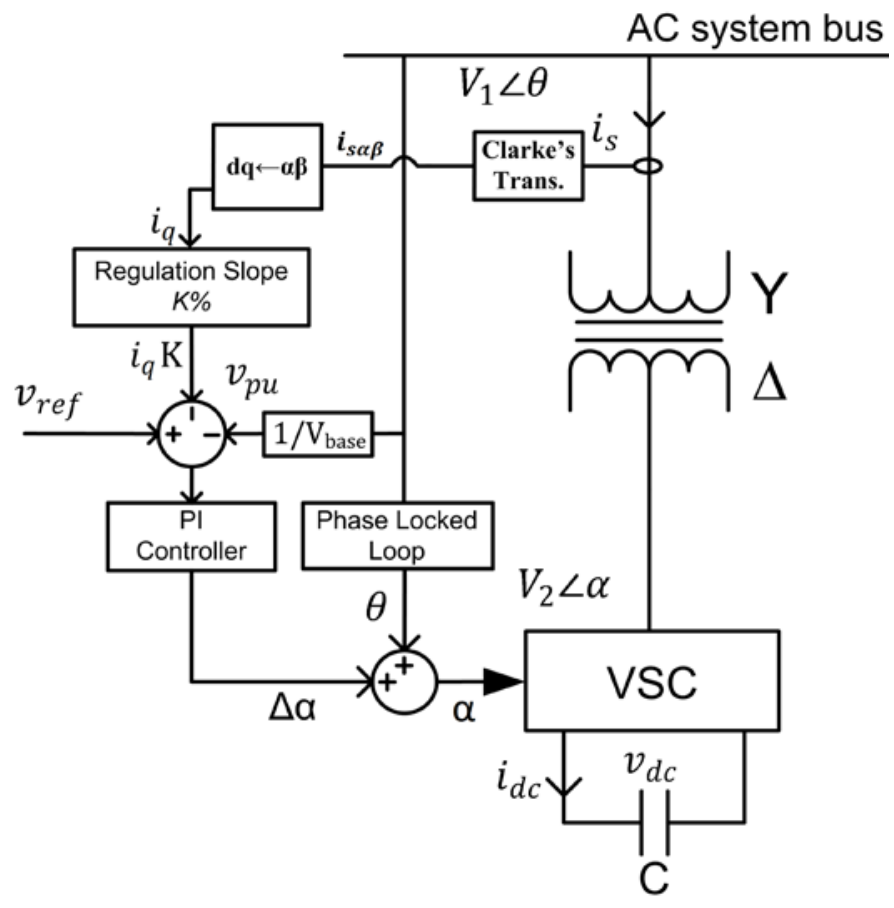

Fig. 2 STATCOM model

The reactive power exchange between the STATCOM and the AC system is controlled via controlling the VSC firing angle $\alpha$ which enable maintaining the voltage at the point of connection within permissible limits. A phase-locked loop (PLL) is used to provide the phase angle $\theta$ of the point of common coupling (PCC) to assure the synchronization between the AC system and the STATCOM output voltage.

The linear operating range of the STATCOM can be 
extended if a regulation "droop" is allowed [32]. Regulation allows the PCC voltage to be slightly below or higher than its nominal value. This can be achieved by adding a compensated output current $k i_{q}$ to a pre-defined reference $v_{r e f}$ creating voltage reference $v_{r e f}^{*}$. This reference value is compared to the per unit voltage of the AC system to create an input to the PI controller whose output $\Delta \alpha$ is used along with $\theta$ to create the firing angle $\alpha$. The compensation component $k i_{q}$ will be negative for capacitive mode and positive for inductive mode.

The regulation slope (droop) $k$ is defined as [32],

$$
k=\frac{\Delta v_{C \max }}{i_{\text {Cmax }}}=\frac{\Delta v_{\text {Lmax }}}{i_{\text {Lmax }}}
$$

where $\Delta v_{C \max }$ is the maximum under voltage deviation at the PCC of the STATCOM and the AC system that is corresponding to maximum capacitive output current $i_{C \max }$, while $\Delta v_{\text {Lmax }}$ is the maximum over-voltage deviation at the same point that is corresponding to maximum inductive output current $i_{\text {Lmax }}$. The regulation slope will control the modulating voltage signal $v_{r e f}^{*}$ so that its value will be higher or less than the nominal reference level $v_{r e f}$ in the case of inductive compensating current and capacitive compensating current respectively until the maximum capacitive or inductive compensating output current is reached.

A PI controller is used to generate a proper firing angle to control the STATCOM output reactive power. The PI controller parameters are selected by using the robust optimization method (Nelder and Mead) [33, 34]. In this optimization method the parameters can be obtained with significantly reduced computational time and effort. Nelder and Mead's algorithm adjusts the PI parameters $\left(K_{I}, K_{P}\right)$ based on how well it minimizes the cumulative objective function $(O F)$. In this paper, the objective function is represented as an integral-squared-error (ISE) that is widely used in steady-state and dynamic optimization problems.

$$
O F=I S E=\int_{t_{0}}^{t_{f}}\left(v_{r e f}+i_{q} k-v_{P C C}\right)^{2} d t
$$

To make the parameters selection robust, for any set of trial parameters, several system runs are conducted as shown in Fig. 3. An $O F\left(K_{I}, K_{P}\right)$ is determined for the entire aggregate of runs, in which each run in the aggregate corresponds to one operating condition of the network.

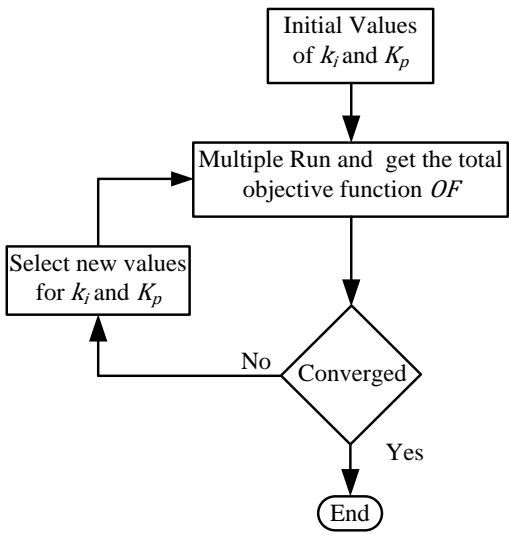

Fig. 3 Flowchart for selecting PI parameters.

\section{Simulation Results}

VSC faults may lead to blocking of the converter, or even disconnection of the wind turbine from the grid to protect them from any possible catastrophic failure. These faults can be caused by component failure or various malfunctions in the control and firing equipment $[11,14]$.

To study the impact of the RSC flashover fault on the voltage profile of the DFIG-based WECS, the system shown in Fig. 1 is used, and the crowbar protection circuit is deactivated. In this study, the machine is initialized with a speed of 1.054 pu to pass the initial transients and is switched to the torque control at $\mathrm{t}=0.5 \mathrm{~s}$. The STATCOM is connected to the point of common coupling of the WECS and the AC grid (bus-1 in Fig. 1).

The voltage profile of the DFIG-based WECS, with and without the STATCOM under a sustained RSC flashover fault is examined. The fault is assumed to take place in the RSC to investigate the impact on the FRT capability of the DFIG. Time domain waveforms for the PCC reactive power, generator terminal voltage, and the voltage at the STATCOM converter terminals $\left(\mathrm{V}_{2}\right.$ in Fig. 2) are investigated. Furthermore, the compliance of the voltage at the PCC of the WECS and the AC grid with various FRT grid codes such as those used in the US, Spain and Germany [35, 36], with and without the proposed controller are examined and compared.

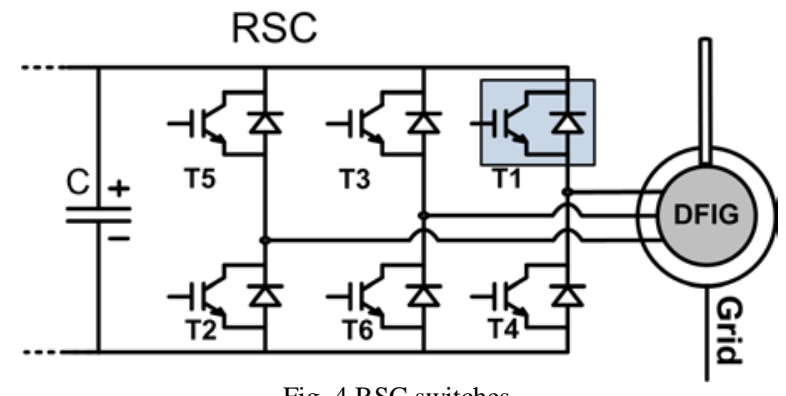

Fig. 4 RSC switches

A flashover across a non-conducting switch results in a line-to line short circuit fault with a very large over-current in the conducting switch on the same side of the voltage source converter [11, 13]. A flashover fault is assumed to take place at the instant that gives the maximum fault current, that is, just at the moment when a switch starts conduction.

A sustained flashover fault was simulated on switch T1 of the RSC at $t=6.31 \mathrm{~s}$. Figs. 5-8 show the performance of the system under study during a sustained IGBT flashover within the RSC. Fig. 5 indicates that during normal operating conditions, the DFIG output reactive power is maintained at zero level to achieve the unity power factor operation as elaborated in section II. Upon fault occurrence at $t=6.31 \mathrm{~s}$, the DFIG draws about 1.8 pu of reactive power from the grid Fig. 5 . The proposed controller acts to increase the voltage at the converter terminals during the fault duration as presented in Fig. 6. As a result, a reactive power support can be immediately provided by the STATCOM, and the reactive power at bus-1 can be regulated and maintained at zero level even though the fault is unremitting. Fig. 7 shows that the 
voltage at the generator terminal experiences voltage sag where the DFIG terminal voltage level was reduced to $0.75 \mathrm{pu}$ This voltage sag issue eliminated and the voltage level can be maintained at its nominal value by regulating the reactive power using STATCOM.

Compared with FRT grid codes of the US, Spain and Germany, the voltage at the PCC will violate the low voltage ride through LVRT level of all grid as seen in Fig. 8. This will call for the disconnection of the wind turbine from the grid. When the STATCOM is connected to the system and due to reactive power compensation, the PCC voltage is regulated to the nominal value during the fault and hence the connection of the wind turbine can be maintained.

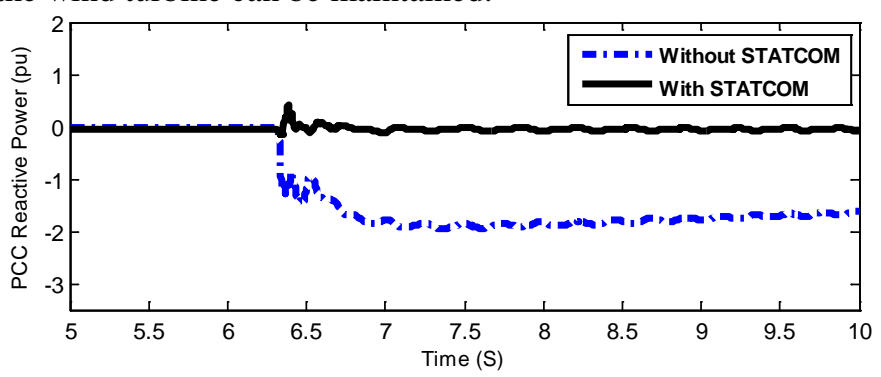

Fig. 5. The PCC reactive power.

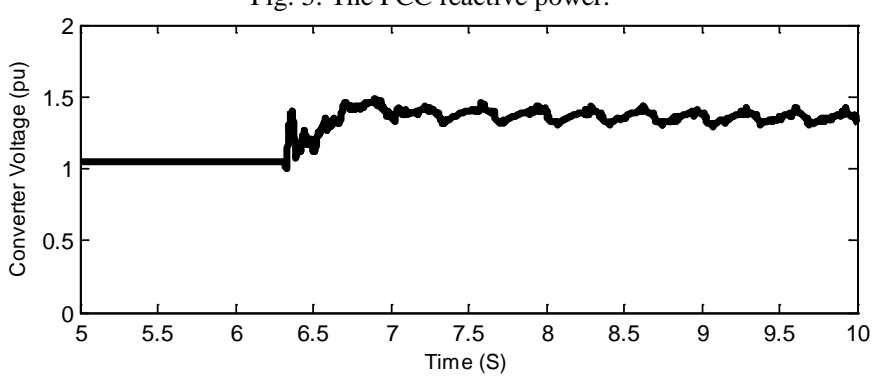

Fig. 6. The converter terminal voltage.

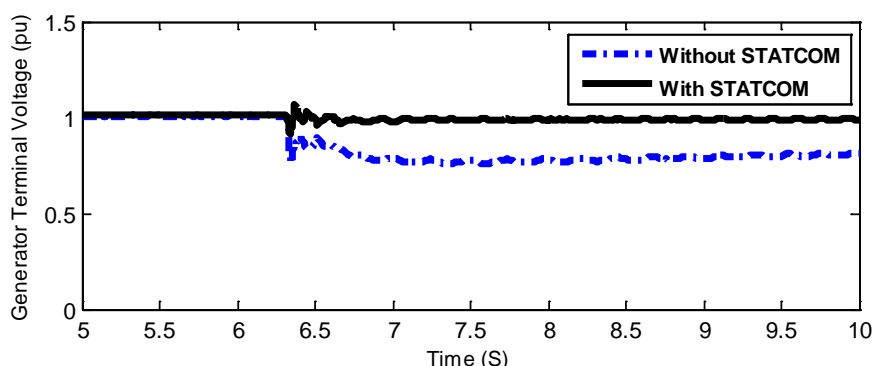

Fig. 7. The generator Terminal voltage.

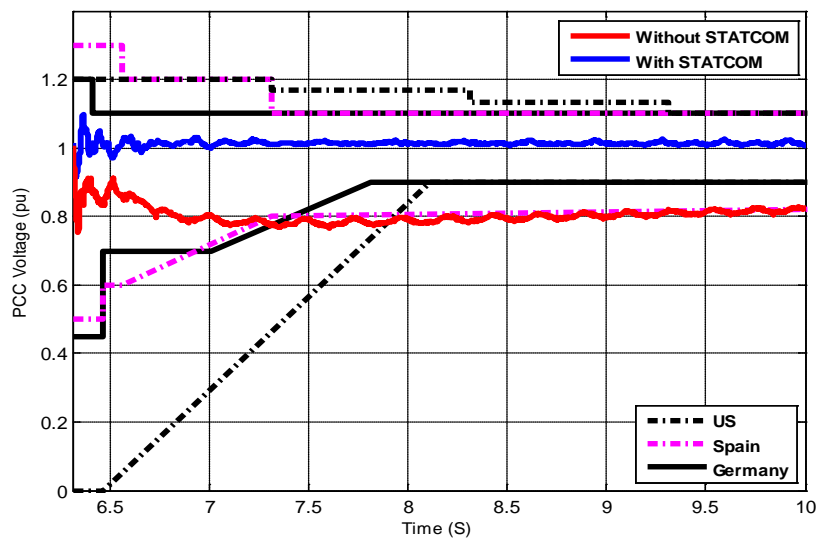

Fig. 8. The PCC voltage compliance with the grid codes. Conclusion

\section{CONCLUSION}

In this paper, the impact of RSC IGBT flashover fault on the FRT capability has been investigated. Simulation results show that the studied fault will lead to the violation of the LVRT levels of the studied grid codes. During this fault the wind turbine should be disconnected from the grid as it is fail to comply with the restriction enforced by the network operators represented by the LVRT. The connection of the STATCOM with the proposed controller mitigates the effects of the studied fault. The results demonstrate that the proposed controller is capable of bringing the voltage profile at the PCC to the nominal steady-state level, maintaining the unity power factor operation of the DFIG and, hence, maintaining the connection of the wind turbine to the grid until either the fault is cleared or the protection scheme activated

\section{REFERENCES}

[1] "Global Wind Statistics 2011," http://www.gwec.net/ 07.02.2012.

[2] P. Musgrove, Wind Power. New York: Cambridge University Press, 2010.

[3] T. Ackermann, Wind Power in Power System. West Sussex: John Wiley and Sons Ltd, 2005.

[4] A. Petersson and S. Lundberg, "Energy Efficiency Comparison of Electrical Systems for Wind Turbines," presented at the Nordic Workshop on Power and Industrial Electronics, Stockholm, Sweden 2002.

[5] C. Zhe, J. M. Guerrero, and F. Blaabjerg, "A Review of the State of the Art of Power Electronics for Wind Turbines," Power Electronics, IEEE Transactions on, vol. 24, pp. 1859-1875, 2009.

[6] J. Lopez, P. Sanchis, X. Roboam, and L. Marroyo, "Dynamic Behavior of the Doubly Fed Induction Generator During Three-Phase Voltage Dips," Energy Conversion, IEEE Transactions on, vol. 22, pp. 709-717, 2007.

[7] A. F. Abdou, A. Abu-Siada, and H. R. Pota, "Effect of Intermittent Voltage Source Converter Faults on the Overall Performance of Wind Energy Conversion System," International Journal of Sustainable Energy, pp. 1-13, 2013.

[8] H. B. A. Sethom and M. A. Ghedamsi, "Intermittent Misfiring Default Detection and Localisation on a PWM Inverter Using Wavelet Decomposition," Journal of Electrical Systems, vol. 4, 2008.

[9] Y. Shaoyong, A. Bryant, P. Mawby, X. Dawei, R. Li, and P. Tavner, "An Industry-Based Survey of Reliability in Power Electronic Converters," Industry Applications, IEEE Transactions on, vol. 47, pp. 1441-1451, 2011.

[10] J. Arrillaga, Y. H. Liu, and N. R. Watson, Flexible power transmission: the HVDC options: John Wiley, 2007.

[11] J. Arrillaga, High voltage direct current transmission: Institution of Electrical Engineers, 1998.

[12] L. Bin and S. K. Sharma, "A Literature Review of IGBT Fault Diagnostic and Protection Methods for Power Inverters," Industry Applications, IEEE Transactions on, vol. 45, pp. 1770-1777, 2009.

[13] K. R. Padiyar, HVDC power transmission systems: technology and system interactions: Wiley, 1990.

[14] L. Bin and S. Sharma, "A survey of IGBT fault diagnostic methods for three-phase power inverters," in Condition Monitoring and Diagnosis, 2008. CMD 2008. International Conference on, 2008, pp. 756-763.

[15] H. Sheng, L. Xinchun, K. Yong, and Z. Xudong, "An Improved LowVoltage Ride-Through Control Strategy of Doubly Fed Induction Generator During Grid Faults," Power Electronics, IEEE Transactions on, vol. 26, pp. 3653-3665, 2011.

[16] A. O. Ibrahim, N. Thanh Hai, L. Dong-Choon, and K. Su-Chang, "A Fault Ride-Through Technique of DFIG Wind Turbine Systems Using Dynamic Voltage Restorers," Energy Conversion, IEEE Transactions on, vol. 26, pp. 871-882, 2011.

[17] A. Rolan, F. Corcoles, and J. Pedra, "Doubly Fed Induction Generator Subject to Symmetrical Voltage Sags," Energy Conversion, IEEE Transactions on, vol. 26, pp. 1219-1229, 2011.

[18] D. Campos-Gaona, E. L. Moreno-Goytia, O. Anaya-Lara, and G. Burt, "Ride-through-fault capabilities of DFIG wind farm connected to a VSC 
station during a DC fault," in AC and DC Power Transmission, 2010. ACDC. 9th IET International Conference on, 2010, pp. 1-5.

[19] L. Xin, Z. Tao, C. Yongning, and W. Weisheng, "Short Circuit Current Characteristic of Wind Generators," in Power and Energy Engineering Conference, 2009. APPEEC 2009. Asia-Pacific, 2009, pp. 1-4.

[20] R.-M. He, J.-L. Wang, J. Ma, Y.-H. Xu, and D. Han, "Impacts of DFIGbased wind farm on load modeling," in Power \& Energy Society General Meeting, 2009. PES '09. IEEE, 2009, pp. 1-6.

[21] A. Abu-Siada and S. Islam, "Application of SMES Unit in Improving the Performance of an AC/DC Power System," Sustainable Energy, IEEE Transactions on, vol. 2, pp. 109-121.

[22] H. A. Darwish, A. M. I. Taalab, and M. A. Rahman, "Performance of HVDC converter protection during internal faults," in Power Engineering Society General Meeting, 2006. IEEE, 2006, p. 7.

[23] S. O. Faried and A. M. El-Serafi, "Effect of HVDC converter station faults on turbine-generator shaft torsional torques," Power Systems, IEEE Transactions on, vol. 12, pp. 875-881, 1997.

[24] A. F. Abdou, A. Abu-Siada, and H. R. Pota, "Application of STATCOM to improve the LVRT of DFIG during RSC fire-through fault," in Universities Power Engineering Conference (AUPEC), 2012 22nd Australasian, 2012, pp. 1-6.

[25] A. F. Abdou, A. Abu-Siada, and H. R. Pota, "DFIG Fault Ride Through Improvement During VSC Faults," Energy Science and Technology, vol. Vol. 5, pp. 17-25, 2013.

[26] K. R. Padiyar and A. M. Kulkarni, "Design of reactive current and voltage controller of static condenser," International Journal of Electrical Power \& Energy Systems, vol. 19, pp. 397-410, 1997.

[27] A. F. Abdou, A. Abu-Siada, and H. R. Pota, "Application of a STATCOM for damping subsynchronous oscillations and transient stability improvement," in Universities Power Engineering Conference (AUPEC), 2011 21st Australasian, 2011, pp. 1-5.

[28] M. Khederzadeh, "Coordination control of statcom and ultc of power transformers," in Universities Power Engineering Conference, 2007. UPEC 2007. 42nd International, 2007, pp. 613-618.

[29] A. F. Abdou, A. Abu-Siada, and H. R. Pota, "Damping of subsynchronous oscillations and improve transient stability for wind farms," in Innovative Smart Grid Technologies Asia (ISGT), 2011 IEEE PES, 2011, pp. 1-6.

[30] L. Shuhui and T. A. Haskew, "Analysis of Decoupled d-q Vector Control in DFIG Back-to-Back PWM Converter," in Power Engineering Society General Meeting, 2007. IEEE, 2007, pp. 1-7.

[31] R. Pena, J. C. Clare, and G. M. Asher, "Doubly fed induction generator using back-to-back PWM converters and its application to variablespeed wind-energy generation," Electric Power Applications, IEE Proceedings -, vol. 143, pp. 231-241, 1996.

[32] N. G. Hingorani and L. Gyugyi, Understanding FACTS: concepts and technology of flexible AC transmission systems: IEEE Press, 2000.

[33] J. A. Nelder and R. Mead, "A Simplex Method for Function Minimization," The Computer Journal, vol. 7, pp. 308-313, January 1, 19651965.

[34] A. M. Gole, S. Filizadeh, and P. L. Wilson, "Inclusion of robustness into design using optimization-enabled transient simulation," Power Delivery, IEEE Transactions on, vol. 20, pp. 1991-1997, 2005.

[35] M. Tsili and S. Papathanassiou, "A review of grid code technical requirements for wind farms," Renewable Power Generation, IET, vol. 3, pp. 308-332, 2009.

[36] M. Altin, O. Goksu, R. Teodorescu, P. Rodriguez, B. B. Jensen, and L. Helle, "Overview of recent grid codes for wind power integration," in Optimization of Electrical and Electronic Equipment (OPTIM), 2010 12th International Conference on, 2010, pp. 1152-1160.

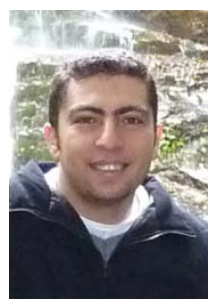

Ahmed Fathi Abdou was born in Egypt, in 1982. He received his B.Sc. and M.Sc. Eng. degrees from Faculty of Engineering, Menoufia University, Egypt, in 2004 and 2007, respectively, all in electrical and power system engineering. He is currently a $\mathrm{PhD}$ candidate at the University of New South Wales, Australian Defence Force Academy. His research interests include distributed generation, renewable energy, smart grids, electrical machines, voltage stability, power electronics, FACTS devices and control applications.

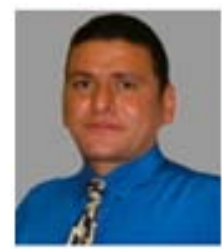

A. Abu-Siada (M’07, SM'12) received his B.Sc. and M.Sc. degrees from Ain Shams University, Egypt and the $\mathrm{PhD}$ degree from Curtin University of Technology, Australia, All in Electrical Engineering. Currently, he is a lecturer in the Department of Electrical and Computer Engineering at Curtin University. Editor-in-Chief for Electrical and Electronics Engineering International Journal (EEEIJ).

His research interests include power system stability, Condition monitoring, Power Electronics, Power Quality, Energy Technology and System Simulation. He is a regular reviewer for the IEEE Transaction on Power Electronics, IEEE Transaction on Dielectrics and Electrical Insulations, and the Qatar National Research Fund (QNRF).

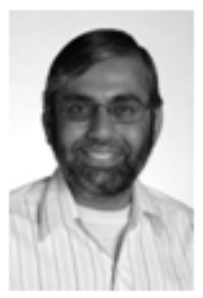

Hemanshu R. Pota received B.E. from Sardar Vallabhbhai Regional College of Engineering and Technology, Surat, India, in 1979, M.E. from the Indian Institute of Science, Bangalore, India, in 1981, and the Ph.D. from the University of Newcastle, NSW, Australia, in 1985; all in Electrical Engineering.

$\mathrm{He}$ is currently an associate professor at the University of New South Wales at the Australian Defence Force Academy, Canberra, Australia. He has held visiting appointments at the University of Delaware; Iowa State University; Kansas State University; Old Dominion University; the University of California, San Diego; and Centre for AI and Robotics, Bangalore. He has a continuing interest in the area of power system dynamics \& control and modelling \& control of mechanical systems such as flexible structures, acoustical systems, and UAVs. 